\title{
A Compilation of Aid Policies for Persons with Intellectual Disabilities in Shanghai City
}

\author{
Mei Liao
}

\section{Definition and Classification of Intellectual Disability (ID)}

The classifying criteria for intellectual disability in practice vary from organization to organization, or specialization to specialization.

Intellectual disabilities comprise intellectual developmental disorder and dementia. In accordance with the China Classification and Diagnosis Criteria for Mental Disorders 3rd Edition (CCMD-3), intellectual developmental disorder refers to some syndromes of mental deficiency or retardation. Persons with the disorder tend to behave at a low grade of average intelligence and with a certain level of difficulty in social adaptation. The disability develops before the age of maturity at 18 , and its syndromes either occur singularly or with complications such as intellectual disorders or physical diseases. Their intelligence grades, by the standardized approach to intelligence testing and assessment, are found to be lower than normal.

In reference to standardized IQ values, intellectual disability can be scaled as shown in Table 1.

Moreover, in accordance with the National Standard of Disability Classification and Scales for Disabled Persons (GB/T26341-2010), disabled children aged 0-6 years are classified into several scales of intellectual disability in reference to their developmental quotients (DQ) and adaptive behaviors. Developmental quotients are referred to for children in the DQ range of less than 72, whereas for those in the DQ range of 72-75, their adaptive behavior is referred to. For children aged 7 years or older, their disabilities are scaled by their IQ values and their adaptive

Mei Liao is the compiler of this chapter.

M. Liao (凶)

Shanghai Shida Public Welfare Foundation, 29F, 999 Middle Huaihai Ro., Shanghai 200031, China

e-mail: mliao23@vip.sina.com 
Table 1 Descriptions of intellectual disability and related IQ ranges

\begin{tabular}{l|l}
\hline Scale description & IQ range \\
\hline Marginal intelligence & $70-86$ \\
\hline Mild intellectual disability & $50-69$ \\
\hline Moderate intellectual disability & $34-49$ \\
\hline Severe intellectual disability & $20-40$ \\
\hline Profound intellectual disability $^{\mathrm{a}}$ & $<20$ \\
\hline
\end{tabular}

${ }^{a}$ Chinese Society of Medicine Psychiatry Branch (compiler), China Classification of Mental Disorders $3^{\text {rd }}$ Edition, "Intellectual Developmental Disability and Mental Developmental Disorders for Children and Teenagers", Jinan: Shandong Science and Technology Press, 2001

Table 2 Scales of intellectual disability

\begin{tabular}{l|l|l|l|l}
\hline Scales & \multicolumn{2}{|l|}{ Intelligence development grade } & \multicolumn{2}{l}{ Social adaptability } \\
\cline { 2 - 5 } & $\begin{array}{l}\text { Developmental } \\
\text { quotient (DQ) for } \\
\text { ages 0-6 }\end{array}$ & $\begin{array}{l}\text { Intelligence } \\
\text { quotient (IQ) for } \\
\text { ages 7+ }\end{array}$ & $\begin{array}{l}\text { Adaptive Behavior } \\
\text { (AB) }\end{array}$ & $\begin{array}{l}\text { WHO-DASII } \\
\text { value for ages 18+ }\end{array}$ \\
\hline Scale 1 & $\leq 25$ & $<20$ & Profound & $\geq 116$ \\
\hline Scale 2 & $26-39$ & $20-34$ & Severe & $106-115$ \\
\hline Scale 3 & $40-54$ & $35-49$ & Moderate & $96-105$ \\
\hline Scale 4 & $55-75$ & $50-69$ & Mild & $52-95$ \\
\hline
\end{tabular}

behavior. If the two are not scored at the same grade, the later reference is preferred. Their ID can be scaled as shown in the Table $2 .^{1}$

Dementia refers to a case of intelligence deficiency due to causal factors such as physical, chemical, or virus-induced injury to the originally normal brain.

Persons with intellectual disabilities interviewed for this book mainly refer to those with intellectual developmental disorder from the fetal or infant period.

\section{Educational Policies}

\section{Children with Profound and Severe ID}

Children with profound intellectual disability are unable to walk outdoors, and thus they may complete their compulsory education via access to direct approaches such as teaching at home.

\footnotetext{
${ }^{1}$ General Administration of Quality Supervision, Inspection and Quarantine of the People's Republic of China Standardization Administration of the People's Republic of China, Disability Classification and Scales for Disabled Persons (GB/T26341-2010), implemented from 2011 onwards.
} 


\section{Children with Profound, Moderate, and Mild ID}

Children with ID are admitted to special public kindergartens and special preschool classes. For mild cases, a special or general class of a public or private kindergarten where children with disabilities are funded by the government in the city applies. After completion of their preschool education, these children may go on to a special 9-year compulsory school. For mild cases, they are assigned to a general school special class, or a full-time general class of such a school together with their normally developing peers.

After their completion of their 9-year compulsory special education, students with ID may, at their own will and capacity through tests, be enrolled to study at elementary vocational and technical schools.

Persons with ID who are able and eligible for further study may attend general secondary specialized schools as well as institutions of higher learning.

Successively from 2004 onwards and across the country, free education has been provided to students with disabilities during their compulsory education. In Shanghai, students with disabilities enjoy free preschool education, compulsory primary up to junior high school education, and even senior high school education. For student with disabilities at senior high schools, apart from tuition waivers, free textbooks, and workbooks, they are also granted an annually sum of 4,000 yuan as a national stipend. For those at specialized secondary schools, they are offered tuition waivers, free textbooks, and workbooks, plus a sum of 2,000 yuan as a national stipend. ${ }^{2}$

Students with disabilities and children living with individuals with disabilities, who study at full-time institutions of higher learning with Shanghai registered permanent residences in financially disadvantaged families, are also eligible for a certain sum of grant-in-aid to cover part of their tuition: a grant of up to 6,500 yuan per academic year for higher vocational education, junior college up to undergraduate levels; 8,000 yuan for postgraduates per academic year; and 10,000 yuan per academic year for $\mathrm{PhD}$ candidates. The aforesaid sums are for the recipient's actual tuition settlements within the amount limits for each academic year.

Children living with disabled family and disabled students, who study at adult education institutions with Shanghai registered permanent residences in financially disadvantaged families, bear $10 \%$ of their adult education tuition. The rest $(90 \%)$ is subsidized to students with disabilities receiving a secondary education with the disabled persons' employment security fund at sums of up to 3,600 yuan; those receiving their junior college education may be given a total of up to 9,000 yuan; those receiving their undergraduate education may receive 13,500 yuan. $^{3}$

\footnotetext{
${ }^{2}$ Shanghai Municipal Education Commission, Shanghai Municipal Bureau of Finance and Shanghai Disabled Persons' Federation, The Circular on Shanghai's Implementation of Free Education to Disabled Students for the Stage of Basic Education. Shanghai Education and Finance Document [2015] No. 103.

${ }^{3}$ Shanghai Disabled Persons' Federation, Shanghai Municipal Bureau of Finance, Shanghai Municipal Education Commission and Shanghai Municipal Bureau of Civil Affairs, The Circular on
} 
This policy may vary from region to region. In some districts or counties of Shanghai municipality, students with disabilities, who receive their secondary education, higher education, adult education, or vocational education, may have their full tuition amounts subsidized by the local government.

\section{Policies on Social Relief and Aid}

\section{Minors with Disabilities}

Subsidies for Rehabilitation Training to children with disabilities at specialized rehabilitation institutions designated by the Shanghai Disabled Persons' Federation are granted by the government in the sum of 15,000 yuan per year for each child with cerebral palsy and 3,000 yuan per year for each child with intellectual disability. ${ }^{4}$

Institutional Care Subsidies are available for persons with disabilities, financially disadvantaged children aged 8-16 years with a Disability Certificate of the People's Republic of China, who are unable to receive a compulsory education because of severe disability and live in a disabled persons caring institution designated by the Shanghai Disabled Persons' Federation. They are granted from the government a monthly sum of 1,000 yuan if eligible for the institutional care service through verification. The institutions that provide care to severely minors with disabilities are granted an additional subsidy of 500 yuan per bed each year. Individuals with disabilities, who receive such supportive policies, are no longer entitled, meanwhile, to the subsidies for rehabilitation training for the disabled aged $8-16$ years. ${ }^{5}$

\footnotetext{
Shanghai's Adjustment of the Subsidy Standard for Disabled Students and Children Living with Poor Households, Shanghai Disabled Persons Federation Document [2016] No. 117.

${ }^{41}$ Shanghai Municipal Health Bureau, Shanghai Municipal Education Commission, Shanghai Municipal Bureau of Finance, and Shanghai Disabled Persons' Federation, The Circular on 2007 Shanghai's Rehabilitation Aid Work Program for 2000 Disabled Children Aged below 7. Shanghai Disabled Federation Document [2007] No. 57; Shanghai Disabled Persons' Federation, Shanghai Municipal Health Bureau, Shanghai Municipal Education Commission, and Shanghai Municipal Bureau of Finance, The Circular on Subsidies to the City's Disabled Children and Minors aged 816 for Their Rehabilitation Training. Shanghai Disabled Federation Document No. [2010] No. 81. Shanghai Municipal Health Bureau, Shanghai Municipal Education Commission, Shanghai Municipal Bureau of Finance, and Shanghai Disabled Persons' Federation, The Circular on Adjustment of the Rehabilitation Aid Subsidies Standard for the City's Children and Minors with Cerebral Palsy and Autism. Shanghai Disabled Federation Document [2012] No. 114.

${ }^{52}$ Shanghai Disabled Persons' Federation, Shanghai Municipal Bureau of Civil Affairs, and Shanghai Municipal Bureau of Finance, The Circular on the City's Institutional Care Subsidies to the Severely Disabled and Impoverished Children and Minors Aged 8-16. Shanghai Disabled Federation Document [2010] No. 80.
} 


\section{Adults with Disabilities}

Living and Nursing Subsidies are available for unemployed disabled persons aged over 16 at the primary (disability Grade I), secondary (disability Grade II), or tertiary (disability Grade III) disability rating scales.

In 2017, for the unemployed and persons with severe disabilities in Shanghai, a sum of 1,270 yuan was granted as a living subsidy.

The living subsidies for financially disadvantaged persons with disabilities are divided into three categories: a monthly sum of 330 yuan to each unemployed person with a severe disability for his or her minimum living provision; 300 yuan for persons with disabilities living with a household receiving basic living allowances; and 200 yuan for persons with disabilities living in a low-income household. Meanwhile, any persons with a disability, who is eligible for any of these three categories, may apply for a higher category with a greater subsidy sum.

The Nursing Subsidies for Persons with Severe Disabilities are divided into two categories: a monthly sum of 300 yuan for each person with a disability rated at disability Grade I, and a monthly sum of 150 yuan for each person with ID rated at disability Grades II and III. Persons with disabilities who already enjoy nursing subsidies are also eligible to apply for access to institutional, household, and relevant nursing services.

The eligible persons with disabilities may also apply for Living Subsidies for Financially Disadvantaged Disabled Persons, as well as Nursing Subsidies for Severely Disabled Persons. ${ }^{6}$

Medical Insurance is raised by the government in full for urban and rural residents with severe disabilities, for which two-thirds of the premium is covered with the disabled persons' employment security fund at the regional or national level in Shanghai, and the remaining third is covered by the social welfare lottery public welfare fund. ${ }^{7}$

Medical Subsidies are granted to persons with severe disabilities insured against their outpatient emergency or household sickbed fees at a starting sum of 300 yuan. Any excess is covered with the medical insurance fund, of which a $70 \%$ payment of the fees from the fund applies to Grade I medical institution outpatient emergencies; a $60 \%$ payment at Grade II; and $50 \%$ at Grade III.

For their hospitalization or emergency room observation fees, the starting sum of payment varies: 50 yuan at Grade I medical institutions; 100 yuan at Grade II medical institutions; and 300 yuan at Grade III medical institutions. The excess is covered with the medical insurance fund, of which a $90 \%$ payment of the fees from

\footnotetext{
${ }^{6}$ Shanghai Municipal Bureau of Civil Affairs, Shanghai Municipal Bureau of Finance, and Shanghai Disabled Persons' Federation, The Circular of Shanghai Municipal Bureau of Civil Affairs Print and Distribution for the Regulations on the Living Subsidies to the Financially Disadvantaged Disabled Persons and Nursing Subsidies to the Severely Disabled Persons. Shanghai Civil Affairs and Welfare Document [2016] No. 1.

${ }^{7}$ The Circular on the Subsidies to the Severely Disabled Persons' Urban and Rural Basic Medical Insurance in Shanghai. Shanghai Disabled Federation Document [2015] No. 158.
} 
the fund applies to the Grade I medical institution hospitalization; $80 \%$ at Grade II; and $70 \%$ at Grade III.

The entire fee for which a patient with severe disabilities must pay at their own expense for medical treatment, inclusive of outpatient expenses, is covered by the government via relief and subsidy. ${ }^{8}$

Institutional Nursing Subsidies are available for the eligible unemployed and persons with severe disabilities, who may apply to the government for access to institutional nursing services with these subsidies. From July 2011 onwards, each eligible person with a disability is subsidized a sum of 700 yuan directly transferred to the account of the nursing institution with any inadequate amount to be complemented by the applicant.

Each district and county in Shanghai, as the case may be, increases nursing subsidies of its own accord. For instance, in Jiading District, institutional care services have reached out to all persons with disabilities in need within the entire district, subsidizing up to a monthly sum of 400 yuan each to the non-severe, unemployed, institutionalized persons with disabilities with minimal assurance families; and up to a monthly sum of 200 yuan to each applicant with disabilities certified and eligible for nursing conditions through examination. ${ }^{9}$

In-Household Care applies to persons with severe disabilities, unemployed in the 16-59 years bracket, who have not yet received institutional nursing or daytime care subsidies. They are eligible to apply for government-funded in-household care services, for whom service workers go to the household of a person with a disability offering $1 \mathrm{~h}$ of nursing on a daily basis, such as housework and living care. ${ }^{10}$

Transport Subsides apply to the certified person with disabilities at ages below 65 years (exclusive of 65) with a Shanghai registered permanent residence, at the monthly sum of 45 yuan each. ${ }^{11}$

Grain and Cooking Oil Poverty-Relief Subsidies apply to persons with severe disabilities and unemployed persons living with a Shanghai urban or rural household receiving the minimal subsistence allowances, or their spouses and children. They are granted monthly grain and cooking oil cards and vouchers. The poverty-relief subsidy

\footnotetext{
${ }^{8}$ The Circular of Shanghai Municipal People's Government's Print and Distribution for the Regulations of Shanghai City on the Urban and Rural Residents' Basic Medical Insurance. Shanghai Government Document [2015] No. 57. The Circular on the Adjustment and Update of the City's Medical Aid System and Enhancement of the Hospitalization Aids. Shanghai Civil Affairs and Aids Document [2015] No. 43.

${ }^{9}$ Shanghai Jiading District, The Opinions on Standardization of the Institutional Nursing Subsidies for Disabled Persons (2012), See http://www.jiading.gov.cn/zwpd/zwdt/content_12633.

${ }^{10}$ Shanghai City's Implementation Programme for the Disabled Persons' Home Care, Shanghai Disabled Federation Document [2009] No. 39; The Circular on the Adjustment of the City's Home Care for the Unemployed Severely Disabled Persons, Shanghai Disabled Federation Document [2014] No. 175.

${ }^{11}$ The Circular of Print and Distribution on the Regulations on the Transport Subsidies to the Disabled Persons in Shanghai, Shanghai Disabled Federation Document [2017] No. 12.
} 
cards include $10 \mathrm{~kg}$ rice, $900 \mathrm{ml}$ cooking oil, and $0.5 \mathrm{~kg}$ table sugar, convertible to a sum of 72 yuan; and $4 \mathrm{~kg}$ rice, convertible to 22 yuan. $^{12}$

\section{Training and Employment}

Sunshine Home, one of the Shanghai Municipal Government's projects in operation in 2005, is a community aid-to-the-disabled training institution for persons with intellectual disabilities in the age bracket of 16-35 years. The home develops activities such as educational training, rehabilitation exercises, Special Olympic sports, and simple labor, helping persons with ID improve their capacity for self-care and social skills while promoting their chances to include themselves into society. The trainees at the home include mostly persons with moderate to severe ID.

The full-time training activity subsidy amounts to 250 yuan per person per month, in addition to the monthly meal subsidy of 150 yuan. The two subsidy categories are funded to the Sunshine Home for its purchase of activity-purposed supplies and consumables as well as for its provision of lunch, drinks, etc., for the trainees. ${ }^{13}$

At present, Shanghai has 241 such homes altogether in all its downtown street neighborhoods and towns. Institutions similar to Sunshine Homes are established across the country, although they may differ slightly in their institutional names.

The Sunshine Vocational Rehabilitation Aids Base, or Sunshine Base, Sunshine workshop, is one of the Shanghai Municipal Government's practical projects of 2010. Taking its communities as its units, it is an informal employment institution designed to organize relatively centralized vocational rehabilitation activities such as production and vocational training for persons with disabilities with employment difficulties. The subjects for aid are persons with mild to moderate disabilities of working age. Through labor and employment training, persons with disabilities gain a basic living provision and their inclusion into society is fostered.

The trainees' pension contributions as well as their medical and unemployment insurance are paid on their behalf; $40 \%$ of the Shanghai urban workers' minimal wages are granted to the trainees as employment subsidies; to those intending to purchase commercial insurance, such as group life accident insurance and additional group health insurance against accidental injury, at an annual subsidy of up to 80 yuan; to the eligible for their lunches, etc.; and to the Sunshine bases' purchase of

\footnotetext{
${ }^{12}$ Shanghai Municipal Bureau of Civil Affairs, Shanghai Municipal Bureau of Finance and Shanghai Municipal Bureau of Grain, The Circular on Further Improvement of Shanghai's Grain and Oil Allowance to Poor Households. Shanghai Civil Affairs Document [2016] No. 20.

${ }^{13}$ Shanghai Disabled Persons Federation and Shanghai Municipal Bureau of Finance, The Circular on Improvement in the Fund Subsidy Allocation for the Sunshine Home. Shanghai Disabled Federation Document [2014] No. 84.
} 
tutorial materials and consumables, at a monthly training subsidy of 250 yuan, and a monthly meal subsidy of 150 yuan. ${ }^{14}$

So far, Shanghai City boasts 170 Sunshine bases, some of which have collaborated and merged with the Sunshine Home. Each trainee is entitled to choose one of these institutions.

The Off-Duty Register is a local practice by which workers with disabilities sign employment contracts with an employer although they do not actually work in the nominated job posts. However, the worker still receives full insurance, as the state stipulates, against the pension fund, medical treatment, unemployment, occupational injury, and child delivery, have their housing funds contributed, and receive a certain wage no less than the city's minimum.

According to the stipulations of the Shanghai Municipal Government, governmental organizations, enterprises, and public institutions shall employ persons with disabilities with the city's registered permanent residence in the proportion of $1.5 \%$ to the total number of on-the-job workers in the workplace in the previous year. ${ }^{15}$ Any workplace that fails to employ workers with disabilities on a pro-rata basis as stipulated shall pay into persons with disabilities employment security fund. After a worker with disabilities registers as off duty, the workplace is entitled to a waiver of the proportionate disabled persons' employment security fund. There are also some local enterprises that rent disability certificates just for exemption from contribution to the fund.

Taking Shanghai as a case in December $2017,{ }^{16}$ the city provided that an employer must pay registered workers with disabilities (or those really employed) the minimum wage and contribute a minimum to the social insurance premium; thus, the employer shall pay each person with disabilities, actually, 3,927 yuan as a minimal monthly wage plus a contribution to the five types of social insurance premiums; ${ }^{17}$ if the

\footnotetext{
${ }^{14}$ Shanghai Disabled Persons' Federation and Shanghai Municipal Bureau of Finance. The Circular on Improvement in Subsidies Grant for the Sunshine Vocational Rehabilitation Aids Base. Shanghai Disabled Federation Document [2014] No. 85.

${ }^{15}$ Before 2017 , employment of the disabled workers at the proportion of $1.6 \%$ to the average number of workers at each workplace in the previous year; from September 2017, changed to collection of the disabled persons' employment security fund at the proportion of $1.5 \%$ to the number of workers. See Shanghai Disabled Persons' Federation, Guidebook to the Disabled Persons' Employment Security Fund in Shanghai. http://www.shdisabled.gov.cn/clwz/clwz/ggl/2017/09/04/ 4028fc765e3cca14015e4c2e1a5a21ad.html?tm=1504864907104.

${ }^{16}$ From 1 April 2017, the minimal monthly wages standard for the workers in Shanghai was increased to 2,300 yuan. See the Shanghai Human Resources and Social Security Document [2017] No. 12, The Circular on Adjustment of the City's Minimal Wages Standard. http://www.12333sh.gov. $\mathrm{cn} / 201412333 / \mathrm{xxgk} / \mathrm{flfg} / \mathrm{gfxwj} / \mathrm{ldbc/gzzl} / 201704 / \mathrm{t} 20170406$ 1253536.shtml. Also from the same date, the Shanghai minimal social insurance premium benchmark was increased to 3,902 yuan. See http://www.12333sh.gov.cn/wsbs/wsbg/2007sbxx/201704/t20170407_1253571.shtml.

${ }^{17} 2300+3902 \times 41.7 \%=3927.13$. Five types of insurance premium can be calculated on the basis of the sum of the pro-rata contribution by the workplace and that of the worker, multiplied by $41.7 \%$, of which, the occupational insurance is calculated by the minimal standard, see 2017 Schedule
} 
employer also contributes to the housing fund for workers with disabilities, each shall be paid at least an additional 306 yuan-thus the actual expenditure of the employer shall be 4,233 yuan. ${ }^{18}$ In the case that the employer does not employ any person with disabilities, but rather chooses to contribute to the employment security fund for persons with disabilities for the inadequate number of workers with disabilities less than $1.5 \%$ as required in proportion to the total number of workers, contributions shall be made through monthly payments of the disabled persons' employment security fund, at the sum of 3,902 yuan each. ${ }^{19}$ In other words, the expenditure on off-duty registration (or actual employment of workers with disabilities) is greater than that of the contribution of a business to the employment security fund for persons with disabilities.

In the beginning, local disabled persons federations and other relevant institutions assisted with persons with disabilities to find off-duty register workplaces. In recent years, in order to facilitate persons with disabilities on-the-job employment and inclusion, disabled persons' federations now do not advocate the off-duty register.

Translated by Chongshun Bai

of Insurance Premium Contribution for Various Insured Personnel via http://www.12333sh.gov. $\mathrm{cn} / 201712333 / \mathrm{bmfw} / \mathrm{bmwd} / \mathrm{zccs} / 01 / 201711 / \mathrm{P} 020171101490742853321$.pdf. Also, in reference to the Shanghai Human Resources and Social Security Document [2017] No. 12, The Circular on Adjustment of the City's Minimal Wages Standard, for the workers who are entitled to receipt of the minimum wage, the employer shall contribute social insurances premium and housing fund, hence the above $41.7 \%$ shall be assumed by the employer (workplace).

${ }^{18}$ The Circular on 2017 Shanghai's Adjustment of Housing Fund Contribution Benchmark, Proportion and Monthly Contribution Minimum/Maximum, Shanghai Provident und Management Committee Document [2017] No. 4. http://www.shgjj.com/html/2017stzzcwj/96358.html.

${ }^{19}$ The equation for calculation of the disabled persons' employment security fund: the annual sum of the security fund contribution $=(1.5 \%$-disabled workers' proportion $) \times$ the sum of the employer's social insurance premium base in the previous year, see the Guidebook to Collection of Disabled Persons' Employment Security Fund in Shanghai. If the total number of workers at the employer is $X$, of which the number of disabled workers is $Y$, for every figure of unemployed disabled workers, the monthly employment security due to the employer is calculated as follows: monthly employment security fund for an unemployed disabled person $=$ the employer's monthly contribution of the disabled persons' employment security fund/number of inadequate employment of the disabled $=$ $\{(1.5 \%-Y / X) \times 3902 \times X\} /\{(1.5 \%-Y / X) \times X\}=3,902$ yuan, equivalent to the social insurance premium base due in the same year. 
Open Access This chapter is licensed under the terms of the Creative Commons AttributionNonCommercial-NoDerivatives 4.0 International License (http://creativecommons.org/licenses/bync-nd/4.0/), which permits any noncommercial use, sharing, distribution and reproduction in any medium or format, as long as you give appropriate credit to the original author(s) and the source, provide a link to the Creative Commons license and indicate if you modified the licensed material. You do not have permission under this license to share adapted material derived from this chapter or parts of it.

The images or other third party material in this chapter are included in the chapter's Creative Commons license, unless indicated otherwise in a credit line to the material. If material is not included in the chapter's Creative Commons license and your intended use is not permitted by statutory regulation or exceeds the permitted use, you will need to obtain permission directly from the copyright holder.

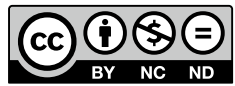

